\title{
Anakinra in the treatment of polyarticular-course juvenile rheumatoid arthritis: safety and preliminary efficacy results of a randomized multicenter study
}

\author{
Norman Ilowite • Oscar Porras • Andreas Reiff • \\ Sue Rudge • Marilynn Punaro • Alan Martin • \\ Roger Allen • Terry Harville • Yu-Nien Sun • \\ Terry Bevirt • Gary Aras • Brent Appleton
}

Received: 5 May 2008 / Revised: 25 July 2008 / Accepted: 4 August 2008 / Published online: 3 September 2008

(C) The Author(s) 2008. This article is published with open access at Springerlink.com

\begin{abstract}
This study assessed the safety and preliminary efficacy of the interleukin-1 receptor antagonist anakinra in patients with polyarticular-course juvenile rheumatoid arthritis (JRA). Eighty-six patients entered a 12-week open-label run-in phase $(1 \mathrm{mg} / \mathrm{kg}$ anakinra daily, $\leq 100 \mathrm{mg} /$ day). Fifty responders were randomized to anakinra or placebo in a 16-week blinded phase, followed by a 12 -month open-label extension $(N=44)$. Due to low enrollment, the primary endpoint was changed from efficacy to safety. The incidence and nature of adverse events were similar across all study phases, with the
\end{abstract}

N. Ilowite

Schneider Children's Hospital,

New Hyde Park, NY, USA

O. Porras

Hospital Nacional de Niños, Dr. Carlos Sáenz Herrera,

San Jose, Costa Rica

A. Reiff

Childrens Hospital Los Angeles,

Los Angeles, CA, USA

S. Rudge

Hutt Hospital,

Lower Hutt, New Zealand

M. Punaro

University of Texas Southwestern,

Dallas, TX, USA

A. Martin

Healthcare Research Consultants,

Tulsa, OK, USA exception of injection site reactions, which were mild to moderate and decreased with time. Anakinra produced a nonsignificant $(P=0.11)$ reduction in disease flares compared with placebo. When normalized to $1 \mathrm{mg} / \mathrm{kg}$ dose, anakinra plasma concentrations were similar to values in adult patients with rheumatoid arthritis. These results indicate that anakinra $1 \mathrm{mg} / \mathrm{kg}$ once daily $(\leq 100 \mathrm{mg} /$ day $)$ is safe and well tolerated in patients with JRA.

Keywords Anakinra - Interleukin-1 $\cdot$ Interleukin-1 receptor antagonist $\cdot$ Juvenile rheumatoid arthritis

R. Allen

Royal Children's Hospital,

Parkville, Victoria, Australia

T. Harville

University of Arkansas for Medical Sciences,

Little Rock, AR, USA

Y.-N. Sun • T. Bevirt • G. Aras • B. Appleton

Amgen Inc.,

Thousand Oaks, CA, USA

N. Ilowite $(\triangle)$

Division of Rheumatology,

Children's Hospital at Montefiore,

Albert Einstein College of Medicine,

3415 Bainbridge Avenue,

Bronx, NY 10467, USA

e-mail: nilowite@montefiore.org 


\section{Introduction}

Juvenile rheumatoid arthritis (JRA) is the most common rheumatic disease of childhood [1-4] and can be associated with uveitis, bone loss, reduced quality of life, and increased mortality $[1,5-8]$. Biologic agents provide a targeted approach to the treatment of JRA, aimed at preventing cytokine-mediated inflammation. Increased production of the proinflammatory cytokine interleukin-1 (IL1) has been implicated in the pathogenesis of rheumatoid arthritis (RA) [9, 10]. A number of publications also support the role of IL-1 in JRA of different onset types [11-14]. Consequently, the IL-1 receptor antagonist (IL-1ra) has been investigated as a therapeutic option to reduce the disease activity and joint damage caused by IL-1 [15].

Anakinra, a recombinant IL-1ra, has demonstrated efficacy in reducing the symptoms of RA (alone or in combination with methotrexate) in randomized controlled trials in adults [16-18] and in small uncontrolled studies of children with JRA $[19,20]$. Treatment of RA patients with anakinra has resulted in decreased radiographic progression and beneficial effects on disease activity. Historically, JRA therapy decisions have been guided by effective therapeutic strategies employed in treating adult RA. Traditional therapies such as disease-modifying antirheumatic drugs (DMARDs) may not adequately control disease progression in JRA, and their use is often limited by adverse events and significant toxicities [21]. New treatment options are needed to improve outcomes in JRA patients. In this current study, we investigated the safety of daily subcutaneous (SC) injections of anakinra in patients with polyarticular-course JRA.

\section{Materials and methods}

\section{Patients}

This study was conducted in compliance with principles of the US Food and Drug Administration and International Conference on Harmonisation Good Clinical Practice regulations/guidelines. The study was approved by the Independent Ethics Committee/Institutional Review Board of each study site, and all patients or guardians provided written informed consent. Patients presenting with polyarticular-course JRA, independent of onset, were eligible for enrollment. Patients were required to have $\geq 5$ swollen joints due to active arthritis (not bony overgrowth) and three joints with limitation of motion at screening and the day 1 visit. Patients were between 2 and 17 years of age, with a minimum weight of $10 \mathrm{~kg}$. Children were to be on a stable dose of methotrexate for 6 weeks before study entry and not receiving biologic therapy within 4 weeks of initiating study drug. The methotrexate dose was kept stable during the open-label and blinded phases of the trial (minimum dose of $10 \mathrm{mg} \mathrm{m}^{-2} \mathrm{wk}^{-1}$ and a maximum dose of $40 \mathrm{mg} / \mathrm{wk}$ ). If administered, doses for nonsteroidal antiinflammatory drug (NSAID) therapy and oral corticosteroids ( $\leq 10 \mathrm{mg}$ /day or $0.2 \mathrm{mg} \mathrm{kg}^{-1}$ day $^{-1}$ of prednisone) had to be kept stable for 4 weeks before the first dose of anakinra and during the course of the trial.

A negative pregnancy test was required for females of childbearing potential. Other exclusion criteria included the following laboratory values: alanine aminotransferase or aspartate aminotransferase $>2.0$ times the upper limit of normal, creatinine $>1.5$ times the upper limit of normal, white blood cell count $<2.0 \times 10^{9} / \mathrm{L}$, neutrophil count $<1.5 \times$ $10^{9} / \mathrm{L}$, or a platelet count of $<150 \times 10^{9} / \mathrm{L}$. Children receiving treatment with a DMARD other than methotrexate could not participate in the study nor could patients receiving intra-articular or systemic corticosteroid injections within 4 weeks before study entry. Patients with clinically significant systemic disease, such as hepatic, renal, neurological, endocrine, cardiac, gastrointestinal (except NSAIDinduced gastrointestinal problems), or hematological disease or presence of symptoms of systemic disease such as intermittent fever, rash, hepatosplenomegaly, or pericarditis, within 24 weeks of the first dose of anakinra, were also excluded.

\section{Study design}

This was a randomized, multicenter, blinded, placebocontrolled study with an open-label run-in period, followed by an open-label extension study (Fig. 1) to evaluate the efficacy and safety of daily SC injections of anakinra in the treatment of JRA (ClinicalTrials.gov \# NCT00037648). However, because of good responses to anti-tumor necrosis factor- $\alpha$ therapy among patients with JRA and the desire of patients and their families to avoid daily injections, enrollment was not sufficient to meet sample size requirements $(n=204)$ that could adequately power, at $80 \%$ or higher, the efficacy analyses. Study objectives were amended primarily to assess the safety of anakinra, with an adjusted enrollment goal of 50 patients. Efficacy analyses were performed to meet obligations under the US Postmarketing Commitment and Pediatric Research Equity Act. The study was conducted at 17 sites in the USA, Canada, Australia, New Zealand, and Costa Rica from July 2000 to February 2004.

Patients received 12 weeks of open-label treatment with anakinra $1 \mathrm{mg} / \mathrm{kg}$ daily, up to a maximum daily administration of $100 \mathrm{mg}$ /day by SC injection. Thereafter, patients meeting the definition of responder (American College of Rheumatology's JRA Core Set Criteria) were randomly assigned (1:1 ratio) to blinded doses of placebo or anakinra for an additional 16 weeks. A responder was defined as 
Fig. 1 Study design. *Patients switched treatment arms if they elected to continue

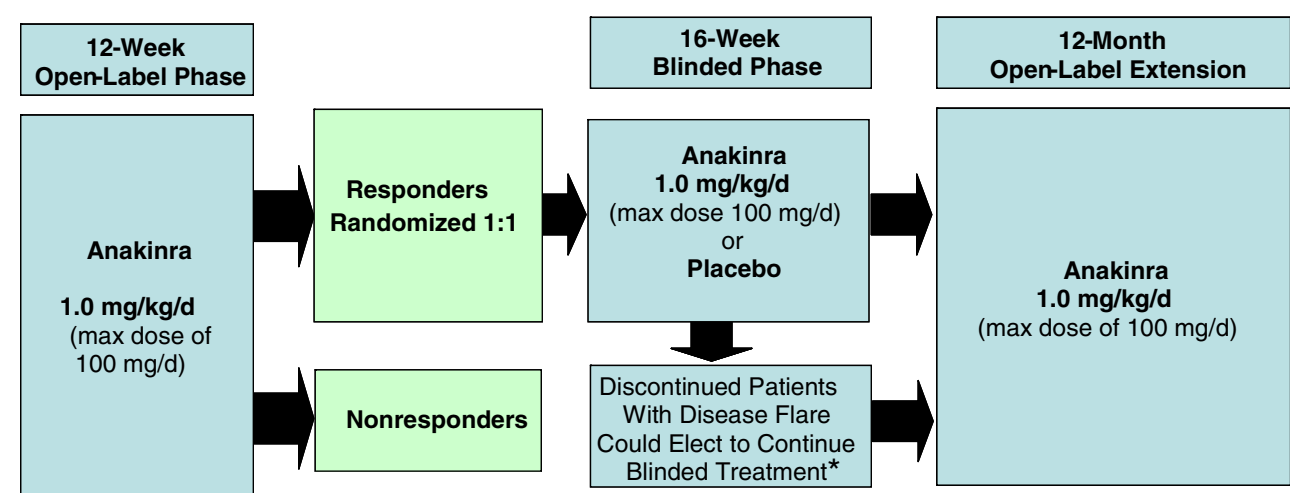

having a $\geq 30 \%$ improvement in three of any six JRA Core Set Criteria variables and with worsening by $\geq 30 \%$ in no more than one of the remaining variables [22]. JRA Core Set Criteria include the following: physician global assessment of disease activity, patient/parent assessment of disease activity, Childhood Health Assessment Questionnaire (CHAQ), number of joints with active arthritis, number of joints with limited range of motion, and erythrocyte sedimentation rate (ESR).

Patients who experienced disease flare during the blinded phase were removed from the primary study but had the option to switch arms (if on "blinded" placebo then switched to "blinded" anakinra, and if on "blinded" anakinra then switched to "blinded" placebo) and continue blinded treatment. Disease flares were defined as (1) $\geq 30 \%$ worsening in at least three of the six JRA Core Set Criteria with improvement in $\leq 1$ of the remaining six JRA Core Set Criteria or (2) a change in at least two active joints or a worsening by at least two units (based on a $0-10$ scale) on either the global assessments or the visual analog scale. Patients had the option to continue anakinra therapy in the open-label extension after the blinded phase. Assessments were conducted at baseline, weeks 2 and 4, and every 4 weeks thereafter in the initial study and then every 3 months in the extension study for up to 12 months.

\section{Study drug}

Study drug was supplied in single-use vials of $100 \mathrm{mg} / \mathrm{mL}$ and was required to be administered once daily by single SC injection by a parent, guardian, caregiver, or the patient, all of whom were instructed regarding the proper injection technique. The placebo formulation was the same but without anakinra. Study drug was administered at approximately the same time each day in the upper thigh, upper arm, or abdomen (rotating injection sites each day).

\section{Study endpoints}

The primary endpoint, safety, was assessed by evaluation of the incidence of treatment-emergent adverse events (includ- ing serious adverse events and infectious episodes) and laboratory values. Immunogenicity was assessed by the proportion of patients testing positive for IL-1 ra antibodies by immunoassay and for neutralizing capabilities by cellbased bioassay. A screening biosensor immunoassay (Biacore, Piscataway, NJ, USA) was used to test for antibody formation to anakinra (at screening, day 1, week 12, and week 28 or on early termination), and positive samples were retested for neutralizing antibodies using a bioassay. Vital signs, blood chemistries, detection of IL-1ra antibodies, adverse events, concomitant medications, emergency room visits and/or hospitalizations, and injection site reactions (ISRs) were evaluated throughout the initial open-label phase, the blinded phase, and the extension study.

Secondary endpoints included measures of efficacy and pharmacokinetics. The primary efficacy endpoint was the proportion of patients with disease flares in the 16-week blinded phase. Other efficacy assessments included time to disease flare and changes in the JRA core components at week 28. Pharmacokinetic assessments were conducted at screening; day 1 ; and weeks $2,4,8,12,16,20,24$, and 28 or early termination to characterize a population profile. Dosing times for each study patient were recorded only on the initial day-1 dose. Consequently, intervals between the time of daily administration of anakinra and the time when blood would be obtained for laboratory testing were not known. Plasma anakinra concentrations were normalized (adjusted) to a daily dose of $1 \mathrm{mg} / \mathrm{kg}$ or a fixed dose of $100 \mathrm{mg}$, and exposure was compared with a previous study in adults with RA [23-25]. Normalization was deemed appropriate because anakinra exhibits linear clearance. To normalize concentrations to a $1 \mathrm{mg} / \mathrm{kg}$ dose for the JRA and adult RA studies, plasma anakinra concentrations were divided by the $\mathrm{mg} / \mathrm{kg}$ dose, and the dose in milligrams was divided by the patient's weight to obtain the dose in milligrams per kilogram. To normalize concentrations to a 100-mg dose, the concentrations were divided by the total dose in milligrams and then were multiplied by 100 . Efficacy and pharmacokinetics were not analyzed in the 12-month extension safety study. 


\section{Statistical analyses}

Safety results were summarized for all patients who received at lease one dose of study medication. Descriptive statistics were used to summarize all data. The proportion of randomized patients with disease flares during the blinded phase in the two treatment groups (anakinra vs placebo) was compared using the Fisher exact test with a two-tailed significance level of 0.05 . The analysis of timeto-disease flare from randomization during the 16-week blinded phase in the intent-to-treat subset was assessed using the log-rank test $(P$ value $=0.05)$.

\section{Results}

\section{Patients}

Patient disposition throughout the three phases of the trial is shown in Fig. 2. Eighty-six patients entered the initial openlabel treatment phase, and 50 patients responded to anakinra therapy and entered the blinded phase of the study; 27 patients $(31 \%)$ were nonresponders. The most common reasons for early withdrawal from the open-label phase were adverse events $(n=4)$ and withdrawal of patient consent $(n=3)$. Thirty-one patients completed the blinded phase. The number of patients who withdrew from the blinded phase was lower in the anakinra group $(n=6)$

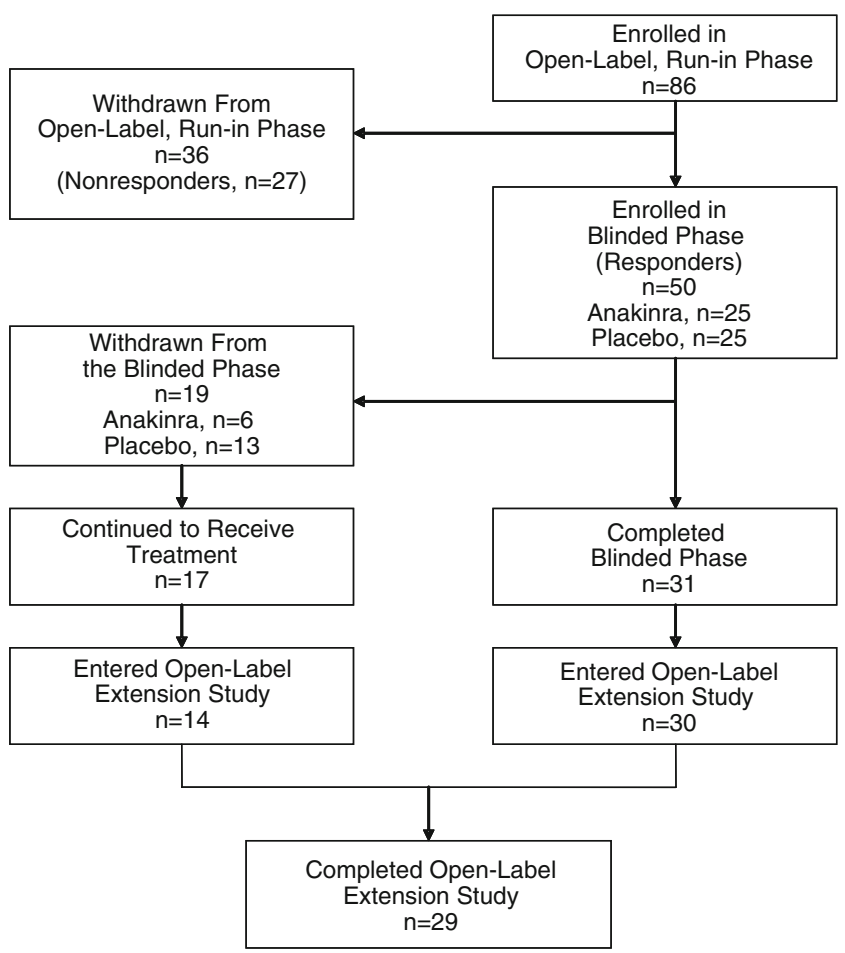

Fig. 2 Patient disposition compared with the placebo group $(n=13)$; most patients withdrew because of disease flare (anakinra, $n=4$; placebo, $n=10$ ). A total of 44 patients were enrolled in the extension study (those who completed the blinded phase $[n=30]$ and those who were terminated from the blinded phase because of disease flare and then elected to enroll in the extension $[n=14])$; most patients discontinued for reasons other than adverse events (e.g., consent withdrawn $[n=3]$, administrative decision $[n=2]$, or lost to follow-up [ $n=2]$ ).

Baseline demographics and clinical characteristics of patients entering the 12-week open-label phase, the 16week double-blind phase, and the extension study were similar among the groups presented (Table 1). Most patients were females, had polyarticular-onset JRA, and had active disease despite methotrexate therapy. In the double-blind phase, the mean duration of JRA was similar in patients receiving anakinra (3.9 years) or placebo (4.2 years). In addition, $76 \%$ of patients receiving placebo and $88 \%$ of patients receiving anakinra were taking methotrexate, $44 \%$ and $76 \%$, respectively, were taking corticosteroids, $16 \%$ and $20 \%$, respectively, were taking other DMARDs, and $4 \%$ and $0 \%$, respectively, were taking NSAIDs.

\section{Safety}

Treatment-emergent adverse events in all phases of the study are presented in Table 2. Adverse events, except ISRs, were similar in nature and occurred with similar frequency in all phases. In the open-label phase, the most common adverse events were ISRs (74\%), upper respiratory infections $(23 \%)$, and headache $(22 \%)$; five events led to withdrawal of four patients (ISR [ $n=3]$, synovitis $[n=1]$, and dysuria $[n=1])$. Injection site pain was experienced by 29 patients (34\%). The most common adverse event causing withdrawal in the open-label phase was ISRs (three patients; 3.5\%). In the blinded phase, the three most common adverse events were ISRs (12\% in each group), upper respiratory infections $(20 \%$ of placebo-treated patients and $16 \%$ of anakinra-treated patients), and headache (4\% of placebo-treated patients and $24 \%$ of anakinratreated patients). No patients withdrew because of an adverse event in the blinded phase. In the extension study, the most common adverse events were arthralgia (23\%), fever $(21 \%)$, and abdominal pain (16\%). Three (7\%) patients withdrew because of an adverse event: one patient with JRA flare, one patient with worsening of JRA, and one patient with nephrosis.

Three serious adverse events were reported in the openlabel phase; however, none were considered by the physician investigator to be related to study medication. No serious adverse events were reported in the blinded phase. In the extension trial, two patients had a total of three serious adverse events: one patient with nephrosis 
Table 1 Patient demographics and clinical characteristics
DMARDs Disease-modifying antirheumatic drugs, JRA juvenile rheumatoid arthritis, NSAIDs nonsteroidal antiinflammatory drugs

\begin{tabular}{|c|c|c|c|c|}
\hline & \multirow{2}{*}{$\begin{array}{l}\text { Open label } \\
(n=86)\end{array}$} & \multicolumn{2}{|c|}{ Double-blind phase } & \multirow{2}{*}{$\begin{array}{l}\text { Extension } \\
(n=44)\end{array}$} \\
\hline & & $\begin{array}{l}\text { Placebo } \\
(n=25)\end{array}$ & $\begin{array}{l}\text { Anakinra } \\
(n=25)\end{array}$ & \\
\hline \multicolumn{5}{|l|}{ Sex, $n(\%)$} \\
\hline Female & $63(73)$ & $18(72)$ & $17(68)$ & $31(70)$ \\
\hline Male & $23(27)$ & $7(28)$ & $8(32)$ & $13(30)$ \\
\hline \multicolumn{5}{|l|}{ Race, $n(\%)$} \\
\hline White & $46(53)$ & $15(60)$ & $13(52)$ & $25(57)$ \\
\hline Black & $5(6)$ & $0(0)$ & $3(12)$ & $2(5)$ \\
\hline Hispanic & $29(34)$ & $10(40)$ & $8(32)$ & $16(36)$ \\
\hline American Indian or Alaska Native & $3(3)$ & $0(0)$ & $1(4)$ & $1(2)$ \\
\hline Asian & $1(1)$ & $0(0)$ & $0(0)$ & $0(0)$ \\
\hline Other & $2(2)$ & $0(0)$ & $0(0)$ & $0(0)$ \\
\hline Mean age, year (range) & $12(3-17)$ & $12(4-17)$ & $10(3-17)$ & $12(4-18)$ \\
\hline Mean weight, kilogram (range) & $40(12-101)$ & $44(16-101)$ & $36(12-98)$ & $44(13-105)$ \\
\hline Mean duration of JRA, year (range) & $4.7(1-16)$ & $4.2(1-16)$ & $3.9(1-11)$ & $4.8(1-7)$ \\
\hline \multicolumn{5}{|l|}{ Type of arthritis at onset, $\mathrm{n}(\%)$} \\
\hline Polyarticular & $62(72)$ & $19(76)$ & $14(56)$ & $29(66)$ \\
\hline Systemic & $15(17)$ & $2(8)$ & $9(36)$ & $10(23)$ \\
\hline Pauciarticular & $9(10)$ & $4(16)$ & $2(8)$ & $5(11)$ \\
\hline \multicolumn{5}{|l|}{ JRA-related medications } \\
\hline Corticosteroids & $50(58)$ & $11(44)$ & $19(76)$ & $27(61)$ \\
\hline DMARDs & $25(29)$ & $4(16)$ & $5(20)$ & $8(18)$ \\
\hline Methotrexate & $67(78)$ & $19(76)$ & $22(88)$ & $38(86)$ \\
\hline NSAIDs & $2(2)$ & $1(4)$ & $0(0)$ & $0(0)$ \\
\hline
\end{tabular}

considered related to study medication (withdrew, see above) and one patient with hepatitis and a viral infection, both considered not related to study medication. The patient who experienced nephrosis was a 16-year-old female who developed bilateral ankle and lower leg edema, hypertension, and proteinuria approximately 3 weeks into the openlabel extension phase of the trial and discontinued anakinra.

Infectious episodes were reported by 35 patients (41\%) in the open-label phase. One case was serious but not considered by the investigator to be related to study medication. In the blinded phase, nine (36\%) patients receiving anakinra and eight $(32 \%)$ patients receiving placebo reported infectious episodes, the most common of which were upper respiratory infection and upper respiratory tract congestion. In the extension study, $16(36 \%)$ patients had an infectious episode; the most common infectious events (reported in at least three patients) were upper respiratory infection (four patients, 9\%), fever (three patients, 7\%), and influenza-like symptoms (three patients, $7 \%$ ). One event (hepatitis due to cytomegalovirus infection) was considered to be serious but was not considered to be related to study medication by the investigator.

In the open-label and blinded phases, laboratory changes during anakinra therapy included transient neutropenia (white blood cell count of $0.79 \times 10^{9} / \mathrm{L}$ on day 141 in one patient that recovered to $1.0 \times 10^{9} / \mathrm{L}$ by the next study visit), anemia (grade 3 based on World Health Organization
Toxicity Criteria [26]; moderate anemia 6.5-7.9 g/dL; hemoglobin decrease in one patient reported on study day 1 only [patient discontinued study on day 1 due to ISR pain]), calcium toxicity (hypercalcemia [12.6-13.4 mg/dL], or hypocalcemia [6.9-6.1 $\mathrm{mg} / \mathrm{dL}]$, grade 3 or higher; reported in one patient who had been taking a calcium supplement prior to the increase), and hepatotoxicity (grade 3 [liver enzyme values 5.1-20 times normal]; elevated alanine aminotransferase reported on day 15 in one patient that did not lead to withdrawal, and no other elevations were reported in this patient). Laboratory changes were not associated with serious adverse events. Similar findings were observed in the extension study, with the exception that one finding (hepatotoxicity) was associated with a serious adverse event (hepatitis and viral infection).

Immunogenicity data were available for 64 patients in the open-label phase, 27 patients in the double-blind phase (placebo, $n=9$; anakinra, $n=18$ ), and 44 patients in the extension trial. In the open-label phase, 48 (75\%) were positive for non-neutralizing anti-IL-1 ra antibodies, and four ( $6 \%$, all nonresponders) had neutralizing antibodies. In the blinded phase, four (44\%) placebo-treated patients and $13(72 \%)$ anakinra-treated patients were positive for antibodies by immunoassay; one patient taking placebo tested positive for neutralizing antibodies. In the extension study, $36(82 \%)$ had confirmed presence of anti-IL-1ra antibodies, but none tested positive for neutralizing antibodies. 
Table 2 Most frequent treatment-emergent adverse events in $\geq 5$ patients in any treatment group by body system category
CNS Central nervous system

${ }^{\mathrm{a}}$ This number in the overall adverse event data differs from that in the infectious episodes data because not all adverse events coded as Respiratory, Infection Upper Respiratory, were considered infectious episodes.

\begin{tabular}{|c|c|c|c|c|}
\hline \multirow[t]{2}{*}{ Adverse event by body system, $n(\%)$} & \multirow{2}{*}{$\begin{array}{l}\text { Open label } \\
\text { Anakinra } \\
(n=86)\end{array}$} & \multicolumn{2}{|c|}{ Double-blind } & \multirow{2}{*}{$\begin{array}{l}\text { Extension } \\
\text { Anakinra } \\
(n=44)\end{array}$} \\
\hline & & $\begin{array}{l}\text { Placebo } \\
(n=25)\end{array}$ & $\begin{array}{l}\text { Anakinra } \\
(n=25)\end{array}$ & \\
\hline Number of patients reporting adverse events & $80(93)$ & $18(72)$ & $17(68)$ & $30(68)$ \\
\hline Application site & $64(74)$ & $3(12)$ & $3(12)$ & $2(5)$ \\
\hline Ecchymosis & $12(14)$ & $1(4)$ & $1(4)$ & 0 \\
\hline Edema & $9(11)$ & 0 & $1(4)$ & 0 \\
\hline Erythema & $31(36)$ & $1(4)$ & $2(8)$ & 0 \\
\hline Inflammation & $8(9)$ & $1(4)$ & 0 & $1(2)$ \\
\hline Pain & $29(33)$ & 0 & 0 & $2(5)$ \\
\hline Pruritus & $26(30)$ & $1(4)$ & $1(4)$ & 0 \\
\hline Rash & $14(16)$ & 0 & 0 & 0 \\
\hline Reaction & $10(12)$ & 0 & $1(4)$ & 0 \\
\hline Body as a whole & $26(30)$ & $5(20)$ & $9(36)$ & $14(32)$ \\
\hline Fever & $14(16)$ & $2(8)$ & $3(12)$ & $9(21)$ \\
\hline Pain & $5(6)$ & $2(8)$ & 0 & $4(9)$ \\
\hline CNS & $21(24)$ & $4(16)$ & $6(24)$ & $8(18)$ \\
\hline Headache & $19(22)$ & $1(4)$ & $6(24)$ & $6(14)$ \\
\hline Gastrointestinal & $29(34)$ & $5(20)$ & $8(32)$ & $13(30)$ \\
\hline Diarrhea & $7(8)$ & 0 & $3(12)$ & $2(4.5)$ \\
\hline Nausea & $7(8)$ & 0 & 0 & $2(4.5)$ \\
\hline Pain, abdominal & $15(17)$ & $2(8)$ & $3(12)$ & $7(16)$ \\
\hline Vomiting & $6(7)$ & 0 & $2(8)$ & $1(2)$ \\
\hline Musculoskeletal & $26(30)$ & $9(36)$ & $7(28)$ & $16(36)$ \\
\hline Arthralgia & $11(13)$ & $4(16)$ & $1(4)$ & $10(23)$ \\
\hline Pain, limb & $6(7)$ & $4(16)$ & $3(12)$ & $5(11)$ \\
\hline Respiratory & $36(42)$ & $7(28)$ & $8(32)$ & $15(34)$ \\
\hline Cough & $5(6)$ & 0 & 0 & $3(7)$ \\
\hline Infection, upper respiratory ${ }^{a}$ & $20(23)$ & $5(20)$ & $4(16)$ & $5(11)$ \\
\hline Sore throat & $5(6)$ & 0 & $2(8)$ & $4(9)$ \\
\hline Skin and appendages & $23(27)$ & $7(28)$ & $2(8)$ & $9(21)$ \\
\hline Rash & $9(11)$ & $3(12)$ & $0(0)$ & $4(9)$ \\
\hline
\end{tabular}

\section{Efficacy}

Compared to baseline, a majority of patients (58\%) achieved a $\geq 30 \%$ improvement in the JRA Core Set Criteria and were considered responders in the 12-week open-label portion of the trial. The highest percentage of responders within a disease subset were those with systemic onset (73\%) compared with pauciarticular (67\%) and polyarticular $(53 \%)$ onset. During the double-blind phase of the trial, fewer patients treated with anakinra had disease flares compared with patients receiving placebo at all time points; at week 28, four (16\%) anakinra patients (two of nine with systemic and two of 14 with polyarticular disease onset) and ten (40\%) placebo patients (one of two with systemic, one of four with pauciarticular, and eight of 19 with polyarticular disease onset) had a disease flare (not significant by Fisher exact test $[P=0.11]$ ). Time to disease flare was greater in patients receiving anakinra, nearly reaching statistical significance ( $P=0.057$ based on logrank test). Compared with the placebo group, patients treated with anakinra demonstrated a slight progressive improvement in mean change in CHAQ at week $28(-0.25$ vs 0.13 ). Patients in the anakinra group also had progressive improvement in ESR through week 28 compared with placebo (-2.21 vs $13.73 \mathrm{~mm} / \mathrm{h})$.

\section{Pharmacokinetics}

Individual concentration-time data for patients receiving anakinra are shown in Fig. 3. With the daily anakinra dose normalized to $1 \mathrm{mg} / \mathrm{kg}$, the range of concentrations was comparable to that observed in adults with RA [23-25]. When the dosage was normalized to $100 \mathrm{mg} /$ day, a trend of higher concentrations was observed compared with adult RA patients. Higher concentration ranges were recorded in children with lower body weight. The mean normalized (to a $1-\mathrm{mg} / \mathrm{kg}$ dose) plasma concentrations of anakinra were 182,259 , and $194 \mathrm{ng} / \mathrm{mL}$ in JRA patients aged 3 to 6,7 to 12 , and 13 to 17 years, respectively, compared with a mean normalized plasma concentration of $221 \mathrm{ng} / \mathrm{mL}$ in adult RA patients. When normalized to a 100-mg daily dose of anakinra, the mean plasma concentrations were 1110,717 
Fig. 3 Anakinra plasma concentrations

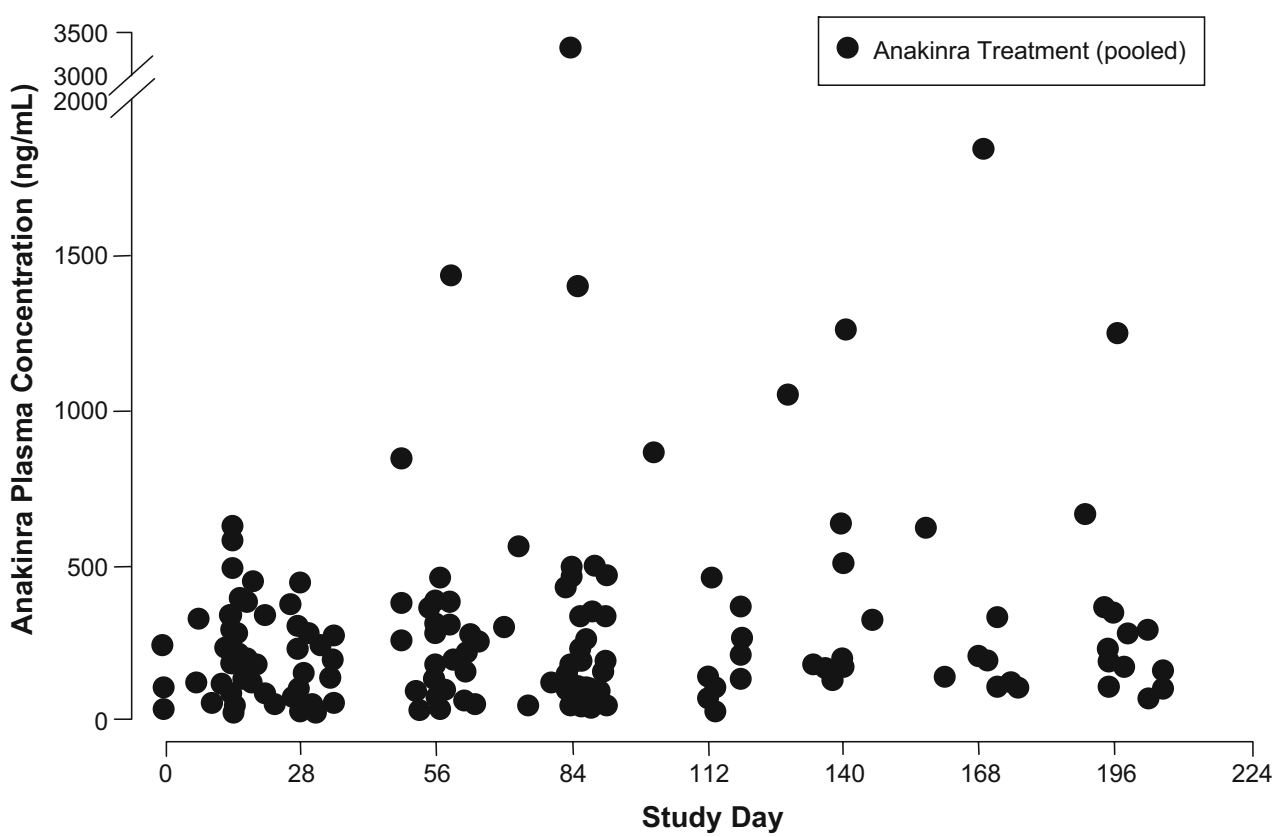

and $420 \mathrm{ng} / \mathrm{mL}$ in JRA patients aged 3 to 6,7 to 12 , and 13 to 17 years, respectively, compared with a mean normalized plasma concentration of $319 \mathrm{ng} / \mathrm{mL}$ in adult RA patients.

\section{Discussion}

The findings from this study indicate that the short-term safety profile of anakinra in juvenile patients is similar to that reported for adults with RA in clinical trials. During the blinded phase, the most common adverse events were ISRs, headache, and upper respiratory infections. Adverse events occurred with a similar incidence in patients receiving anakinra or placebo. Across all phases of the study, few adverse events were serious or led to study withdrawal. Similar to other subcutaneously administered biologics, ISRs appeared to be common with daily use of anakinra, occurred early in the trial, and resolved over time. The frequency of ISRs decreased in the double-blind period compared with the open-label phase, which is consistent with findings in adults in which ISRs were more common with the initial period of dosing and transient in duration [27]. In contrast, one patient (4\%) receiving placebo experienced headache as compared with six patients (24\%) who received anakinra. No patients withdrew from the study owing to headache. Furthermore, it should be noted that headache has been reported in up to $28 \%$ of adolescent patients with JRA [28] and that the incidence of headache in this study was consistent with this previous report.

Considering the increased risk of infection associated with rheumatic diseases [29] and biologic agents [30], infectious episodes associated with anakinra therapy repre- sent an important safety concern, particularly in children. Infection rates in this study were low and generally consistent with other trials evaluating anakinra in adults with RA [27, 30]. In a 6-month randomized, placebocontrolled, double-blind study followed by an open-label phase for up to 3 years, only $8 \%(n=105)$ of adult RA patients receiving anakinra $(n=1346)$ experienced a serious infection, with pneumonia being the most frequent [27]. In adults, there were also three events of opportunistic infection (atypical mycobacterial infection, histoplasmosis, and candida esophagitis) occurring between 5 months to 2.5 years after initiating anakinra [27]. In a prospective cohort study of RA patients $(n=70)$ receiving anakinra for up to 1 year, $13 \%$ of the patients experienced an infection, two of which were considered serious [30]. In this present study, the occurrence of serious infections during exposure to anakinra was low. In the open-label phase, one patient experienced severe impetigo, but this was not considered by the investigator to be related to the study medication. No serious infections were reported during the blinded phase, and one patient in the extension phase reported a serious viral hepatitis infection that was not considered related to study medication. There were no reports of opportunistic infections. These results are generally consistent with safety data for other biologic therapy (etanercept) in JRA [31-33].

Although there are limited data regarding the efficacy of anakinra in JRA, published reports suggest that anakinra may reduce symptoms and joint damage in patients with systemic-onset JRA $[19,20]$. A recent study in 20 patients with systemic-onset juvenile idiopathic arthritis reported that anakinra was effective in some patients, with $50 \%$ and $25 \%$ of patients achieving $30 \%$ and $50 \%$ improvements, respectively, in American College of Rheumatology (ACR) 
pedi core set criteria [34]. Recent data also support anakinra as second-line therapy for systemic-onset juvenile idiopathic arthritis, with six of seven patients from a case series in the UK experiencing rapid early improvement in systemic symptoms and joint disease [35]. Irigoyen et al. [19] reported findings from a multicenter retrospective chart review of systemic-onset JRA patients $(n=7)$ receiving anakinra. The majority of treated patients (six of seven) experienced rapid (in as little as 2 weeks) improvement in joint symptoms (as measured by reduction in active joints). Pascual et al. [20] reported similar findings with significant improvement ( $P=0.006$ compared with baseline) in arthritis symptoms (active joint count) at 2 months after initiation of anakinra treatment in nine patients (aged 4-17 years) with systemic-onset JRA who were unresponsive to conventional treatment. A post hoc analysis by subgroup in the current analysis showed that two of nine systemic onset JRA patients flared in the anakinra group and one of two flared in the placebo group.

In addition, Pascual et al. [20] demonstrated that IL-1 gene expression is up-regulated in the peripheral blood mononuclear cells of patients with active systemic onset JRA, supporting the premise that IL-1 may be a mediator of the inflammatory cascade of patients with active systemiconset JRA. Further support for the role of IL-1 in systemiconset disease in children comes from a recent analysis in which complete responders to anakinra in patients with this condition appear to be characterized by the presence of distinct clinical features [36].

The results of the pharmacokinetic analyses demonstrated that weight-based dosing with $1 \mathrm{mg} / \mathrm{kg} \mathrm{SC}$ daily provides adequate anakinra exposure in children with JRA. Plasma concentrations appeared to show a trend to higher levels in JRA patients when normalized to a fixed 100 -mg daily dose than observed in adults. However, when normalized to a weight-based dose of $1 \mathrm{mg} / \mathrm{kg}$, anakinra concentrations were comparable to those in adults.

In summary, anakinra $1 \mathrm{mg} / \mathrm{kg}$ administered as a SC injection once daily (up to a maximum of $100 \mathrm{mg}$ /day) was well tolerated in pediatric patients with JRA. Infection rates were low, and no clinically significant abnormalities in laboratory data were observed. Efficacy results were not conclusive because of the small sample size. Pharmacokinetic assessments indicated that a daily dosage of $1 \mathrm{mg} / \mathrm{kg}$ administered SC provided adequate exposure for the treatment of JRA. Safety data from this study were consistent with results from larger studies in adults and indicated that anakinra was safe and well tolerated in patients with JRA.

Acknowledgments The authors wish to thank Nancy Sheridan and David Stokes, $\mathrm{PhD}$, whose work was funded by Amgen Inc., for providing assistance in the drafting of this manuscript. This study was funded by Amgen Inc.
Disclosures Norman Ilowite has received consulting fees from Amgen and Xoma. Andreas Reiff has received consulting fees from Abbott, Amgen, Pfizer, Merck, and Wyeth. Yu-Nien Sun, Terry Bevirt, Gary Aras, and Brent Appleton are employees of Amgen. Oscar Porras, Sue Rudge, Marilynn Punaro, Alan Martin, Roger Allen, and Terry Harville have no conflicts to disclose.

Open Access This article is distributed under the terms of the Creative Commons Attribution Noncommercial License which permits any noncommercial use, distribution, and reproduction in any medium, provided the original author(s) and source are credited.

\section{References}

1. Borchers AT, Selmi C, Cheema G, Keen CL, Shoenfeld Y, Gershwin ME (2006) Juvenile idiopathic arthritis. Autoimmun Rev 5:279-298

2. Taylor J, Erlandson D (2001) Pediatric rheumatic diseases. In: Clinical care of the rheumatic diseases. American College of Rheumatology, Atlanta, GA

3. Gare A (1999) Juvenile arthritis - who gets it, where and when? A review of current data on incidence and prevalence. Clin Exp Rheumatol 17:367-374

4. Towner SR, Michet CJ Jr, O'Fallon WM, Nelson AM (1983) The epidemiology of juvenile arthritis in Rochester, Minnesota 1960 1979. Arthritis Rheum 26:1208-1213

5. Henderson CJ, Cackwell GD, Specker BL, Sierra RI, Wilmott RW, Campaigne BN, Lovell DJ (1997) Predictors of total body bone mineral density in non-corticosteroid-treated prepubertal children with juvenile rheumatoid arthritis. Arthritis Rheum 40:1967-1975

6. Kotaniemi K, Aho K, Kotaniemi A (2001) Uveitis as a cause of visual loss in arthritides and comparable conditions. J Rheumatol 28:309-312

7. Sawyer MG, Whitham JN, Roberton DM, Taplin JE, Varni JW, Baghurst PA (2004) The relationship between health-related quality of life, pain and coping strategies in juvenile idiopathic arthritis. Rheumatology (Oxford) 43:325-330

8. Welbury RR, Thomason JM, Fitzgerald JL, Steen IN, Marshall NJ, Foster HE (2003) Increased prevalence of dental caries and poor oral hygiene in juvenile idiopathic arthritis. Rheumatology (Oxford) 42:1445-1451

9. Feige U, Karbowski A, Rordorf-Adam C, Pataki A (1989) Arthritis induced by continuous infusion of hr-interleukin-1 alpha into the rabbit knee-joint. Int J Tissue React 11:225-238

10. Fontana A, Hengartner H, Weber E, Fehr K, Grob PJ, Cohen G (1982) Interleukin 1 activity in the synovial fluid of patients with rheumatoid arthritis. Rheumatol Int 2:49-53

11. Saxena N, Aggarwal A, Misra R (2005) Elevated concentrations of monocyte derived cytokines in synovial fluid of children with enthesitis related arthritis and polyarticular types of juvenile idiopathic arthritis. J Rheumatol 32:1349-1353

12. Havemose-Poulsen A, Sorensen LK, Bendtzen K, Holmstrup P (2007) Polymorphisms within the IL-1 gene cluster: effects on cytokine profiles in peripheral blood and whole blood cell cultures of patients with aggressive periodontitis, juvenile idiopathic arthritis, and rheumatoid arthritis. J Periodontol 78:475-492

13. Kutukculer N, Caglayan S, Aydogdu F (1998) Study of proinflammatory (TNF-alpha, IL-1alpha, IL-6) and T-cell-derived (IL-2, IL-4) cytokines in plasma and synovial fluid of patients with juvenile chronic arthritis: correlations with clinical and laboratory parameters. Clin Rheumatol 17:288-292 
14. Madson KL, Moore TL, Lawrence JM 3rd, Osborn TG (1994) Cytokine levels in serum and synovial fluid of patients with juvenile rheumatoid arthritis. J Rheumatol 21:2359-2363

15. Geiger T, Towbin H, Cosenti-Vargas A, Zingel O, Arnold J, Rordorf C, Glatt M, Vosbeck K (1993) Neutralization of interleukin-1 beta activity in vivo with a monoclonal antibody alleviates collagen-induced arthritis in DBA/1 mice and prevents the associated acute-phase response. Clin Exp Rheumatol 11:515522

16. Cohen S, Hurd E, Cush J, Schiff M, Weinblatt ME, Moreland LW, Kremer J, Bear MB, Rich WJ, McCabe D (2002) Treatment of rheumatoid arthritis with anakinra, a recombinant human interleukin-1 receptor antagonist, in combination with methotrexate: results of a twenty-four-week, multicenter, randomized, double-blind, placebo-controlled trial. Arthritis Rheum 46:614 624

17. Cohen SB, Moreland LW, Cush JJ, Greenwald MW, Block S, Shergy WJ, Hanrahan PS, Kraishi MM, Patel A, Sun G, Bear MB (2004) A multicentre, double blind, randomised, placebo controlled trial of anakinra (Kineret), a recombinant interleukin 1 receptor antagonist, in patients with rheumatoid arthritis treated with background methotrexate. Ann Rheum Dis 63:1062-1068

18. Nuki G, Bresnihan B, Bear MB, McCabe D (2002) Long-term safety and maintenance of clinical improvement following treatment with anakinra (recombinant human interleukin-1 receptor antagonist) in patients with rheumatoid arthritis: extension phase of a randomized, double-blind, placebo-controlled trial. Arthritis Rheum 46:2838-2846

19. Irigoyen P, Olson J, Hom C, Ilowite NT (2004) Treatment of systemic onset juvenile rheumatoid arthritis with anakinra [abstract]. Arthritis Rheum 50(suppl):S437-438

20. Pascual V, Allantaz F, Arce E, Punaro M, Banchereau J (2005) Role of interleukin-1 (IL-1) in the pathogenesis of systemic onset juvenile idiopathic arthritis and clinical response to IL-1 blockade. J Exp Med 201:1479-1486

21. Johnson CJ, Reilly KM, Murray KM (2001) Etanercept in juvenile rheumatoid arthritis. Ann Pharmacother 35:464-471

22. Giannini EH, Ruperto N, Ravelli A, Lovell DJ, Felson DT, Martini A (1997) Preliminary definition of improvement in juvenile arthritis. Arthritis Rheum 40:1202-1209

23. Yang B, Frazier J, McCabe J, Young J (2000) Population pharmacokinetics of recombinant interleukin-1 receptor antagonist (anakinra) in subjects with rheumatoid arthritis (RA) [abstract]. Arthritis Rheum 43(suppl):S153

24. Yang B, Frazier J, McCabe J, Young J (2001) Population pharmacokinetics (PK) of anakinra in subjects with rheumatoid arthritis RA [abstract]. Ann Rheum Dis 60(suppl 1):161

25. Bresnihan B (2001) The safety and efficacy of interleukin-1 receptor antagonist in the treatment of rheumatoid arthritis. Semin Arthritis Rheum 30:17-20
26. WHO (World Health Organization) Toxicity Criteria (2008) Available via http://www.fda.gov/cder/cancer/toxicityframe.htm. Cited February 6, 2008

27. Fleischmann RM, Tesser J, Schiff MH, Schechtman J, Burmester GR, Bennett R, Modafferi D, Zhou L, Bell D, Appleton B (2006) Safety of extended treatment with anakinra in patients with rheumatoid arthritis. Ann Rheum Dis 65:1006-1012

28. Shaw KL, Southwood TR, Duffy CM, McDonagh JE (2006) Health-related quality of life in adolescents with juvenile idiopathic arthritis. Arthritis Rheum 55:199-207

29. Doran MF, Crowson CS, Pond GR, O'Fallon WM, Gabriel SE (2002) Frequency of infection in patients with rheumatoid arthritis compared with controls: a population-based study. Arthritis Rheum 46:2287-2293

30. Listing J, Strangfeld A, Kary S, Rau R, von Hinueber U, Stoyanova-Scholz M, Gromnica-Ihle E, Antoni C, Herzer P, Kekow J, Schneider M, Zink A (2005) Infections in patients with rheumatoid arthritis treated with biologic agents. Arthritis Rheum 52:3403-3412

31. Giannini EH, Ilowite NT, Lovell DJ, Wallace CA, Rabinovich EC, Reiff AO (2006) A phase 4 registry of etanercept in children with juvenile rheumatoid arthritis. [abstract THU0456]. Ann Rheum Dis $65: 253$

32. Lovell DJ, Giannini EH, Reiff A, Jones OY, Schneider R, Olson JC, Stein LD, Gedalia A, Ilowite NT, Wallace CA, Lange M, Finck BK, Burge DJ, Pediatric Rheumatology Collaborative Study Group (2003) Long-term efficacy and safety of etanercept in children with polyarticular-course juvenile rheumatoid arthritis: interim results from an ongoing multicenter, open-label, extendedtreatment trial. Arthritis Rheum 48:218-226

33. Lovell DJ, Reiff A, Jones OY, Schneider R, Nocton J, Stein LD, Gedalia A, Ilowite NT, Wallace CA, Whitmore JB, White B, Giannini EH (2006) Long-term safety and efficacy of etanercept in children with polyarticular-course juvenile rheumatoid arthritis. Arthritis Rheum 54:1987-1994

34. Lequerre T, Quartier P, Rosellini D, Alaoui F, De Bandt M, Mejjad O, Kone-Paut I, Michel M, Dernis E, Khellaf M, Limal N, Job-Deslandre C, Fautrel B, Le Loet X, Sibilia J (2008) Interleukin-1 receptor antagonist (anakinra) treatment in patients with systemiconset juvenile idiopathic arthritis or adult onset Still disease: preliminary experience in France. Ann Rheum Dis 67:302-308

35. Ohlsson V, Baildam E, Foster H, Jandial S, Pain C, Strike H, Ramanan AV (2008) Anakinra treatment for systemic onset juvenile idiopathic arthritis (SOJIA). Rheumatology (Oxford) 47:555-556

36. Gattorno M, Piccini A, Lasiglie D, Tassi S, Brisca G, Carta S, Delfino L, Ferlito F, Pelagatti MA, Caroli F, Buoncompagni A, Viola S, Loy A, Sironi M, Vecchi A, Ravelli A, Martini A, Rubartelli A (2008) The pattern of response to anti-interleukin-1 treatment distinguishes two subsets of patients with systemiconset juvenile idiopathic arthritis. Arthritis Rheum 58:1505-1515 